\title{
A unusual case of multifocal pyogenic abscess formation following ERCP procedure
}

\author{
Fahed Merei ${ }^{1 \dagger}$, Galina Shapiro ${ }^{2 \dagger}$, Ibrahim Abu Shakra' ${ }^{1}$, Amitai Bickel ${ }^{1,3}$, Samer Ganam¹, Maxim Bez ${ }^{2}$ and \\ Eli Kakiashvili ${ }^{1,3^{*}}$
}

\begin{abstract}
Background: Endoscopic retrograde cholangiopancreatography (ERCP) is essential for managing biliary and pancreatic disorders. Infection is the most morbid complication of ERCP and among the most common causes of ERCP-related death.

Case presentation: A 69-year-old man presented with right upper quadrant abdominal pain, obstructive jaundice and abnormal liver function tests. Ultrasound revealed cholelithiasis without bile duct dilation. After receiving intravenous antibiotics for acute cholecystitis, the patient was discharged. Two weeks later, an endoscopic ultrasound demonstrated gallstones and CBD dilation of up to $6.4 \mathrm{~mm}$ with 2 filling defects. An ERCP was performed with a papillotomy and stone extraction. Twenty-four hours post-ERCP the patient developed a fever, chills, bilirubinemia and elevated liver function tests. Ascending cholangitis was empirically treated using Ceftriaxone and Metronidazole. However, the patient remained febrile, with a diffusely tender abdomen and elevated inflammatory markers. A CT revealed a very small hypodense lesion in the seventh liver segment. Extended-spectrum beta-lactamase positive Klebsiella Pneumonia and Enterococcus Hirae were identified, and the antibiotics were switched to Imipenem and Cilastatin. The hypodense lesion in the liver increased to $1.85 \mathrm{~cm}$ and a new hypodense lesion was seen in the right psoas. At day 10 post-ERCP, the patient started having low back pain and difficulty walking. MRI revealed L4-L5 discitis with a large epidural abscess, spanning L1-S1 and compressing the spinal cord. Decompressive laminectomy of $L 5$ was done and Klebsiella pneumonia was identified. Due to continued drainage from the wound, high fever, we performed a total body CT which revealed increased liver and iliopsoas abscess. Decompressive laminectomy was expanded to include L2-L4 and multiple irrigations were done. Gentamycin and Vancomycin containing polymethylmethacrylate beads were implanted locally and drainage catheters were placed before wound closure. Multidisciplinary panel discussion was performed, and it was decided to continue with a non invasive approach .
\end{abstract}

(Continued on next page)

\footnotetext{
* Correspondence: elik@gmc.gov.il

${ }^{\dagger}$ Fahed Merei and Galina Shapiro contributed equally to this work.

${ }^{1}$ Department of Surgery A, Galilee Medical Center, Nahariya, Israel

${ }^{3}$ Faculty of Medicine in the Galilee, Bar-llan University, Safad, Israel

Full list of author information is available at the end of the article
}

(c) The Author(s). 2020 Open Access This article is licensed under a Creative Commons Attribution 4.0 International License, which permits use, sharing, adaptation, distribution and reproduction in any medium or format, as long as you give appropriate credit to the original author(s) and the source, provide a link to the Creative Commons licence, and indicate if changes were made. The images or other third party material in this article are included in the article's Creative Commons licence, unless indicated otherwise in a credit line to the material. If material is not included in the article's Creative Commons licence and your intended use is not permitted by statutory regulation or exceeds the permitted use, you will need to obtain permission directly from the copyright holder. To view a copy of this licence, visit http://creativecommons.org/licenses/by/4.0/ The Creative Commons Public Domain Dedication waiver (http://creativecommons.org/publicdomain/zero/1.0/) applies to the data made available in this article, unless otherwise stated in a credit line to the data. 
(Continued from previous page)

Conclusions: Early recognition of complications and individualized therapy by a multi-disciplined team is important for managing post-ERCP septic complications. Particular attention should be given to adequate coverage by empiric antibiotics.

Keywords: Post-endoscopic retrograde cholangiopancreatography, Complications, Ascending cholangitis, Epidural abscess, Psoas abscesses

\section{Background}

Endoscopic retrograde cholangiopancreatography (ERCP) is an increasingly applied endoscopic technique. It is used for both therapeutic (eg, bile duct stone removal) and diagnostic interventions in the bile and pancreatic ducts [1]. The latter include: tissue sampling from biliary or pancreatic lesions, sphincter of Oddi manometry, and diagnostic pancreatoscopy or cholangiography [2]. However, as less-invasive diagnostic tools, such as magnetic resonance cholangiopancreatography and endoscopic ultrasound have become widespread, the proportion of ERCP for therapeutic purposes increased from $66 \%$ in the early 1990 s [3] to $89 \%$ in the late 2000 s [4]. Therefore, ERCP has become largely performed for therapeutic interventions $[5,6]$.

Nonetheless, when compared to other endoscopic techniques, ERCP presents a higher potential for serious complications [7]. The major complications of ERCP include pancreatitis, cholangitis and duodenal perforation; and may be classified by site, timing and severity $[8,9]$. Various rare complications have been reported as well, including gallstone ileus, liver abscess and splenic, hepatic and vascular trauma. Despite technological progress and scientific guidelines, ERCP-related morbidity and mortality have not decreased over time $[4,10,11]$. Many independent risk factors for post-ERCP complications have been identified including operator, hospital, method (eg sphincterotomy) and patient-related factors $[1,11]$.

A particularly morbid group of post-ERCP complications are infections [7], which are frequently caused by enteric bacteria $[12,13]$. The most common septic complication is ascending cholangitis [14], which typically presents within 24 to $72 \mathrm{~h}$ post-ERCP $[15,16]$. The cause is most often incomplete drainage of an infected and obstructed biliary system, which leads to elevated biliary pressure, and subsequently to biliary-venous reflux [17]. Clinical presentation may include the triad of Charcot or the Reynolds pentad, or their components, and may be associated with a liver abscess $[18,19]$. The treatment for ascending cholangitis is based on decompression, antibiotics and supportive care.

Pyogenic liver abscess (PLA) is a life threatening complication of biliary tree infection post ERCP procedure, with mortality rate reach $12 \%$ [20], however Metastasis infection from a pyogenic liver abscess by hematogenous spread to other organs or spaces include epidural abscess or iliopsoas abscess is a potential complication. in our case we will present a rare case of spinal epidural abscess (SEA) originating from a PLA post-ERCP cholangitis.

\section{Case presentation}

A 69-year-old man presented to the emergency department with right upper quadrant abdominal pain that started after a fatty meal. His medical history included diabetes mellitus, hypertension and ischemic heart disease. His surgical history included coronary artery bypass grafting, appendectomy and an inguinal hernia repair. He was hemodynamically stable and afebrile with obstructive jaundice.

Physical examination demonstrate a right upper quadrant tenderness, murphy sign was negative. Lab tests exhibited, normal leukocystes, increased hepatocellular enzymes (total bilirubin $2.6 \mathrm{mg} / \mathrm{dl}$, direct bilirubin 1.17 $\mathrm{mg} / \mathrm{dl}$ ) and liver function test abnormalities (GGT 1255 U/L, ALT 480 U/L, AST 297 U/L, ALP 194 U/L). An abdominal Ultrasonography revealed fatty liver and a normal size gallbladder without thickened walls,with gallstones without bile duct dilation. Even though US imaging did not demonstrate signs of an inflamed gallbladder, the patient was considered to have cholecystitis with obstructive jaundice due to a convincing clinical presentation and remarkable right upper quadrant tenderness, he was admitted to our surgical department and managed conservatively with intravenous antibiotics and supportive care. The patient improved clinically,lab tests was improved also, bilirubinemia was decreased to 1.9/ $0.7 \mathrm{mg} / \mathrm{dl}$ and he was discharged; interval cholecystectomy was recommended following an endoscopic ultrasound (EUS).

Two weeks after discharge the patient underwent an EUS, which demonstrated a gallbladder with gallstones and sludge. Biliary duct dilation of up to $6.4 \mathrm{~mm}$ with 2 filling defects were also visualized. An ERCP was recommended and performed a week and a half later. A papillotomy and stone fragment extraction using a balloon catheter and a basket were performed. After the ERCP, the patient was admitted to our department for observation. Twenty-four hours post-ERCP the patient developed a fever $\left(38^{\circ} \mathrm{C}\right)$, chills, hyperbilirubinemia (2.66/ 

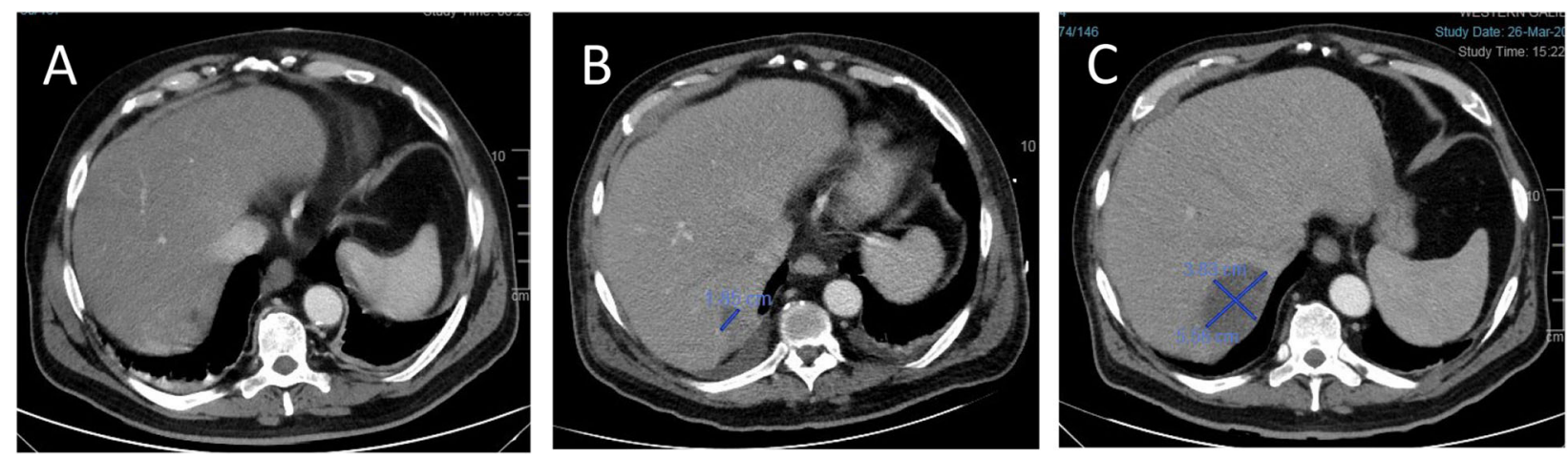

Fig. 1 Liver abscess development on consecutive double contrast abdominal computed tomography scans. Scans were done on days 3 (a) 7 (b) and 26 (c) post-endoscopic retrograde cholangiopancreatography

$1.16 \mathrm{mg} / \mathrm{dl}$ ) and elevated liver function tests (AST 224 U/L, ALT $121 \mathrm{U} / \mathrm{L}$, ALP $160 \mathrm{U} / \mathrm{L}$, GGT $570 \mathrm{U} / \mathrm{L})$. Ascending cholangitis was empirically treated using Ceftriaxone and Metronidazole. However, he continued to be febrile, confused and with chills. His physical examination was remarkable, his abdomen was diffusely tender and his lab tests reveal an increasing in inflammatory markers: C-reactive protein (CRP) $256 \mathrm{mg} / \mathrm{l}$, leukocytosis $14(\times 10 \quad[3] /$ ul),with left shift $92 \%$ neutrophils. Also markedly hyperbilirubinemia was observed (total bilirubin $5.53 \mathrm{mg} / \mathrm{dl}$ ), Blood cultures were drawn to rule out a viscous perforation. A computed tomography (CT) scan with double contrast of the abdomen and pelvis was done 3 days post-ERCP. A perforation was ruled out as no abdominal free air or fluids were found. Yet a very small hypodense lesion was found in the seventh liver segment (Fig. 1a).

On day 6 post-ERCP, the antibiotic regimen was changed to Ertapenem and Vancomycin, to treat possible multi-drug resistant pathogens. Two days later, extended-spectrum beta-lactamase positive Klebsiella Pneumonia and Enterococcus Hirae were identified on blood cultures so antibiotics were switched to Imipenem and Cilastatin. Nonetheless, the patient continued to have abdominal pain. Upon examination, his abdomen was soft and distended, with no signs of peritonitis. CRP was elevated $(160 \mathrm{mg} / \mathrm{L})$, with mild leukocytosis (13 x $10 \mathrm{e}^{3} / \mathrm{uL}$ ) and neutrophilia (83\%). CT scan, with a double contrast of the abdomen and pelvis was repeated on day 7 post-ERCP revealing a hypodense irregular lesion that was found to increase in diameter, this finding was consistent with pyogenic liver abscess (Fig. 1b). Also, a hypodense lesion in the right psoas appeared (Fig. 2b), which was not seen on the first CT scan (Fig. 2a), it was decided to continue with antibiotic treatment without drainage. Two days after the antibiotic regimen was changed to Imipenem and Cilastatin, the abdominal pain subsided. He was afebrile and his liver function tests and bilirubin normalized. However, on day 10 post-ERCP, the patient began to complain about low back pain and difficulty walking. On physical examination, he had localized tenderness over the spinous processes of L4-L5, and reduced quadriceps femoris strength (3/5). A thoracolumbar spine magnetic resonance imaging (MRI) scan was recommended by a consulting orthopedic surgeon to evaluate for possible myelopathy or radiculopathy.
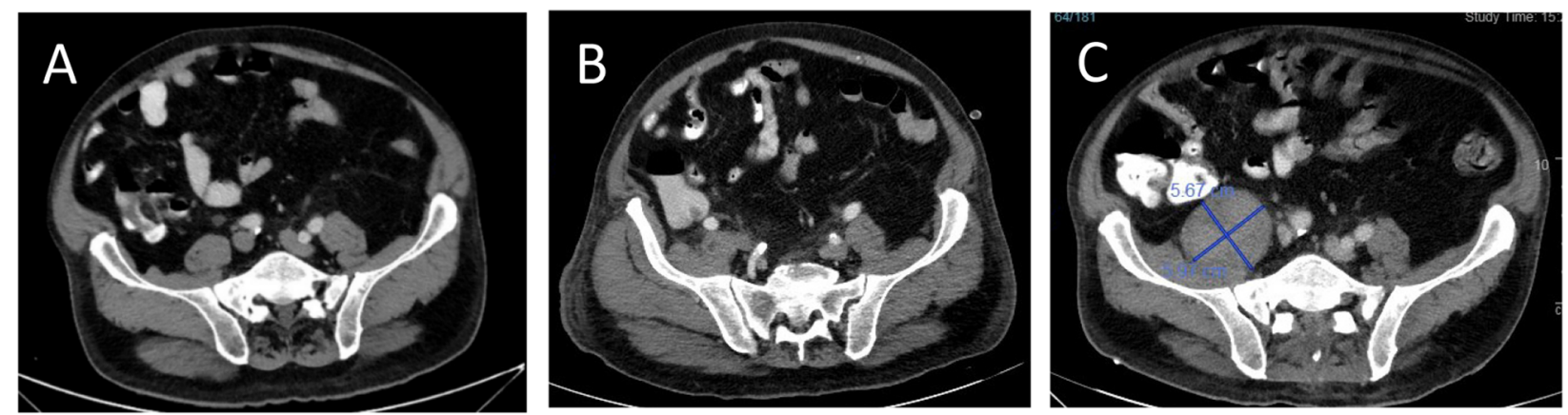

Fig. 2 Psoas abscess development on consecutive double contrast abdominal computed tomography scans. Scans were done on days 3 (a) 7 (b) and 26 (c) post- endoscopic retrograde cholangiopancreatography ERCP 
MRI was performed on day 19 post ERCP, which revealed L4-L5 discitis,a large iliopsoas abscess on the right side,and other small abscess on the left side, an epidural abscess in front of spinal canal at level L1-D11 other one at level L2- S1 appearing to compress the spinal cord (Fig. 3). A diagnosis of spinal epidural abscess (SEA) with discitis and osteomyelitis was established. The patient was transferred to the orthopedic department and was urgently operated. Decompressive laminectomy of L5 was done and a large epidural abscess was drained and irrigated. Drainage catheters were placed, and the wound was closed in layers. Cultures from the pus were positive for Klebsiella pneumonia. Thus, IV antibiotics with polymyxin E and Gentamicin were initiated Post-operatively, and the patient's back pain significantly subsided. Nonetheless, due to continued of serosanguineous drainage from the surgical incision, fever of $38.7^{\mathrm{C}}$, CT total body was performed on day 7 postoperative to evaluate epidural and liver abscess, exhibited a $4.8 \mathrm{~cm}$ hypodense irregular lesion at segment 7 of the liver,epidural and psoas abscess were increased in size (Figs. 1c,2c). patient was taken back to the operating room for other evaluation. The decompressive laminectomy was expanded to include L2-L4, and multiple irrigations were done. Gentamycin and Vancomycin containing polymethylmethacrylate beads were implanted locally and drainage catheters were placed before wound closure. The patient was continued intravenous antibiotics with polymyxin $\mathrm{E}$ and Gentamicin. Two days later the patient was presented to the multidisciplinary panel (surgery and radiology) for further evaluation and discussion of liver and iliopsoas abscess treatment options. In light of the clinician and laboratory improvement it was decided to continue with a non invasive approach and to complete 6 weeks of antibiotic treatment. During the subsequent days the patient's condition improved, the surgical incision was inspected without signs of infection or leak, and his lap tests normalized. Two months later,abdominal and spinal cord CT scan was performed as part of the follow up examination which assured almost complete regression of liver and iliopsoas abscess. An interval cholecystectomy was performed 6 weeks after discharging.

\section{Discussion and conclusions}

In this case report, we presented a patient with multiple rare septic complications after a therapeutic ERCP. To our knowledge, this is the first time that this specific constellation of complications has been reported in the context of ERCP. Our patient presented with a PLA post ERCP procedure, predisposing factors for this infection are diabetes mellitus and post ERCP cholangitis [21]. empiric therapy was promptly started, bacteremia probably resulted in the subsequent septic complications,

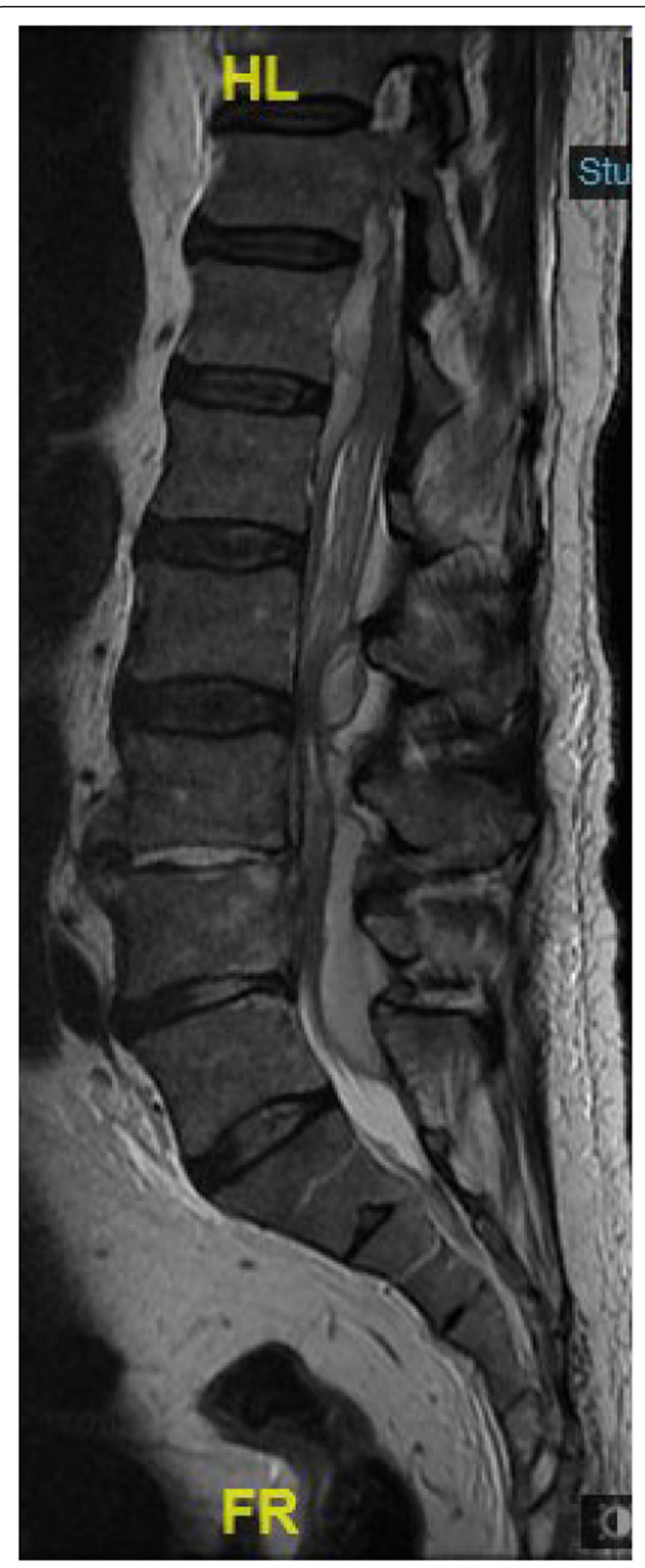

Fig. 3 Spinal epidural abscess as seen on magnetic resonance imaging of the lumbar spine on day 19 post-endoscopic retrograde cholangiopancreatography

including a liver abscess. There is high rates of bacteremia in PLA which can lead to distant infection metastasis to other organs or spaces, especially in K.pneumonia pathogen [22]. Spinal epidural abscess 
(SEA) as metastatic infection originate from PLA still a rare complication, some case reports mentioned the association of a metastatic K.pneumoniae bacteremia and PLA to other spaces like cervical abscess or SEA [23]. SEAs have 5\% mortality rate due to massive sepsis [24], and unfortunately the prognosis of SEA still poor due to delay in diagnosis, in our case early diagnosis of SEA was established and efficient treatment was initiated. Usually PLAs are polymicrobial with enteric facultative and anaerobic. The most commonly gram negative bacilli identified in PLAs are E.coli and Klebsiella pneumonia [25].

Another possible reason for the development of bacteremia in our patient was inadequate coverage by empiric antibiotics. In a study conducted in two German tertiary centers, empiric antibiotics did not cover the full biliary pathogen spectrum in $78 \%$ of the cases [26]. Furthermore, multi-drug resistant bacteria were isolated in $29 \%$ of the patients, including extended-spectrum betalactamase producing organisms. These findings raise the question as to whether empiric treatment for cholangitis, and specifically hospital-acquired cholangitis, should be modified to cover more pathogens or to routinely cover multi-drug resistant organisms. Presumably, earlier treatment of our patient with a better suited antibiotic regiment could have shortened or even prevented bacteremia and thereby reduced the risk for further septic complications.

In conclusion, we presented a patient with PLA caused by post ERCP cholangitis,subsequent with K.pneumoniae bacteremia and metastatic spread to SEA and iliopsoas [22]. He was treated with both medical and surgical treatment. A multidisciplinary treatment team of general surgeons, an infectious disease specialist, orthopedic surgeons and radiologists were needed to care for this patient. As ERCP is expected to become more common, it is important that all clinicians should be aware of the possibility of rare complications of this procedure therefore Early diagnosis of complications and prompt therapy should be key in the management of these patients.

\section{Abbreviations}

ERCP: Endoscopic retrograde cholangiopancreatography; CRP: C-reactive protein; CT: Computed tomography; MRI: Magnetic resonance imaging

\section{Acknowledgements}

Not applicable.

\footnotetext{
Authors' contributions

FM drafted the work and substantively revised it. GS drafted the work and substantively revised it. IAB drafted the work and substantively revised it. $A B$ participated in the preparation of the manuscript. SG performed the literature review. MB participated in patient data collection and image revisions. EK drafted the work and substantively revised it. All the authors have approved the submitted version. All the authors have agreed to be personally accountable for their own contributions and to ensure that questions related to the accuracy or integrity of any part of the work, even ones in which they were not personally involved, are appropriately
}

investigated and resolved, and the resolution documented in the literature. All the authors have approved the submitted version (and any substantially modified version that involves the author's contribution to the study). All the authors have agreed both to be personally accountable for the their own contributions and to ensure that questions related to the accuracy or integrity of any part of the work, even ones in which they were not personally involved, are appropriately investigated, resolved, and the resolution documented in the literature.

Funding

The authors received no funding for this work.

Availability of data and materials

Data sharing is not applicable to this article as no datasets were generated or analysed during the current study.

Ethics approval and consent to participate Not applicable.

\section{Consent for publication}

Written informed consent was obtained from the patient for publication of this Case report and any accompanying images. A copy of the written consent is available for review by the Editor of this journal.

\section{Competing interests}

The authors declare that they have no competing interests.

\section{Author details}

${ }^{1}$ Department of Surgery A, Galilee Medical Center, Nahariya, Israel. ${ }^{2}$ Medical Corps, Israel Defense Forces, Ramat Gan, Israel. ${ }^{3}$ Faculty of Medicine in the Galilee, Bar-Ilan University, Safad, Israel.

Received: 28 November 2019 Accepted: 28 April 2020

Published online: 06 May 2020

References

1. Coelho-Prabhu N, Shah ND, Van Houten H, Kamath PS, Baron TH. Endoscopic retrograde cholangiopancreatography: utilisation and outcomes in a 10-year population-based cohort. BMJ Open. 2013;3(5):e002689.

2. Costamagna G, Familiari P, Marchese M, Tringali A. Endoscopic biliopancreatic investigations and therapy. Best Pract Res Clin Gastroenterol. 2008;22(5):865-81.

3. Loperfido S, Angelini G, Benedetti G, et al. Major early complications from diagnostic and therapeutic ERCP: a prospective multicenter study. Gastrointest Endosc. 1998;48(1):1-10.

4. Kapral C, Muhlberger A, Wewalka F, et al. Quality assessment of endoscopic retrograde cholangiopancreatography: results of a running nationwide Austrian benchmarking project after 5 years of implementation. Eur $\mathrm{J}$ Gastroenterol Hepatol. 2012;24(12):1447-54.

5. Palazzo L, Girollet PP, Salmeron M, et al. Value of endoscopic ultrasonography in the diagnosis of common bile duct stones: comparison with surgical exploration and ERCP. Gastrointest Endosc. 1995;42(3):225-31.

6. Soto JA, Barish MA, Yucel EK, Siegenberg D, Ferrucci JT, Chuttani R. Magnetic resonance cholangiography: comparison with endoscopic retrograde cholangiopancreatography. Gastroenterology. 1996;110(2):589-97.

7. ASoP C, Chandrasekhara V, Khashab MA, et al. Adverse events associated with ERCP. Gastrointest Endosc. 2017;85(1):32-47.

8. Cotton PB, Lehman G, Vennes J, et al. Endoscopic Sphincterotomy complications and their management - an attempt at consensus. Gastrointest Endosc. 1991;37(3):383-93.

9. Aliperti G. Complications related to diagnostic and therapeutic endoscopic retrograde cholangiopancreatography. Gastrointest Endosc Clin N Am. 1996; 6(2):379-407.

10. Siiki A, Tamminen A, Tomminen T, Kuusanmaki P. ERCP procedures in a Finnish community hospital: a retrospective analysis of 1207 cases. Scand J Surg. 2012;101(1):45-50.

11. Glomsaker T, Hoff G, Kvaloy JT, et al. Patterns and predictive factors of complications after endoscopic retrograde cholangiopancreatography. $\mathrm{Br}$ J Surg. 2013;100(3):373-80. 
12. Anderson DJ, Shimpi RA, McDonald JR, et al. Infectious complications following endoscopic retrograde cholangiopancreatography: an automated surveillance system for detecting postprocedure bacteremia. Am J Infect Control. 2008:36(8):592-4

13. Llach J, Bordas JM, Almela M, et al. Prospective assessment of the role of antibiotic prophylaxis in ERCP. Hepatogastroenterology. 2006;53(70):540-2.

14. Andriulli A, Loperfido $S$, Napolitano G, et al. Incidence rates of post-ERCP complications: a systematic survey of prospective studies. Am J Gastroenterol. 2007;102(8):1781-8.

15. Deviere J, Motte S, Dumonceau JM, Serruys E, Thys JP, Cremer M. Septicemia after endoscopic retrograde cholangiopancreatography. Endoscopy. 1990;22(2):72-5.

16. Boender J, Nix G, De Ridder M, et al. Endoscopic sphincterotomy and biliary drainage in patients with cholangitis due to common bile duct stones. Am J Gastroenterol. 1995.

17. Subhani JM, Kibbler C, Dooley JS. Antibiotic prophylaxis for endoscopic retrograde cholangiopancreatography (ERCP). Aliment Pharmacol Ther. 1999;13(2):103-16.

18. Davion T, Braillon A, Delamarre J, Delcenserie R, Joly J-P, Capron J-P. Pseudomonas aeruginosa liver abscesses following endoscopic retrograde cholangiography. Dig Dis Sci. 1987;32(9):1044-6.

19. Katsinelos $P$, Dimiropoulos $S$, Katsiba D, et al. Pseudomonas aeruginosa liver abscesses after diagnostic endoscopic retrograde cholangiography in two patients with sphincter of Oddi dysfunction type 2. Surg Endosc. 2002

20. Mohsen AH, Green ST, Read RC, McKendrick MW. Liver abscess in adults: ten years experience in a UK centre. QJM. 2002:95(12):797-802.

21. Chen $M$, Wang $L$, Wang $Y$, et al. Risk factor analysis of post-ERCP cholangitis: a single-center experience. Hepatobiliary Pancreat Dis Int. 2018;17(1):55-8.

22. Lederman ER, Crum NF. Pyogenic liver abscess with a focus on Klebsiella pneumoniae as a primary pathogen: an emerging disease with unique clinical characteristics. Am J Gastroenterol. 2005;100(2):322-31.

23. Kuramochi G, Takei SI, Sato M, Isokawa O, Takemae T, Takahashi A. Klebsiella pneumoniae liver abscess associated with septic spinal epidural abscess. Hepatol Res. 2005;31(1):48-52.

24. Darouiche RO. Spinal epidural abscess. N Engl J Med. 2006;355(19):2012-20.

25. Johannsen EC, Sifri CD, Madoff LC. Pyogenic liver abscesses. Infect Dis Clin N Am. 0.

26. Reuken PA, Torres $D$, Baier $M$, et al. Risk factors for multi-drug resistant pathogens and failure of empiric first-line therapy in acute cholangitis. PLoS One. 2017;12(1):e0169900.

\section{Publisher's Note}

Springer Nature remains neutral with regard to jurisdictional claims in published maps and institutional affiliations.

Ready to submit your research? Choose BMC and benefit from:

- fast, convenient online submission

- thorough peer review by experienced researchers in your field

- rapid publication on acceptance

- support for research data, including large and complex data types

- gold Open Access which fosters wider collaboration and increased citations

- maximum visibility for your research: over $100 \mathrm{M}$ website views per year

At $\mathrm{BMC}$, research is always in progress.

Learn more biomedcentral.com/submissions 